\title{
Prática social: uma estratégia para ensinar e aprender a Geografia
}

José Maria Leite

Botelho*

Resumo: O presente artigo é resultado de discussões e de reflexões a respeito da prática docente do professor de geografia e da necessidade da inserção da prática social no ensino aprendizagem da geografia escolar. O objetivo deste trabalho é fomentar uma reflexão a respeito da importância que o conhecimento geográfico representou no processo histórico de formação da ciência geográfica, sua transformação em componente curricular obrigatório, tecer considerações a respeito da prática social dos professores e, relacionar o ensino da geografia escolar à Pedagogia Histórico-Crítica.

\section{Social practice: a strategy for teaching and learning the school Geography}

Abstract: The present article is the result of discussions and reflections about the teaching of professor of geography and necessity of social practice teaching placement learning school of geography. The objective of this paper is to promote a reflection on the importance of the geographical knowledge represented in the historical process of the formation of geographical science, its transformation into a compulsory curriculum component considerations about the social practice of teachers and school geography education relate to Critical-historical Pedagogy.
* Mestre em Educação e Professor no Departamento de Geografia da Universidade Federal de Rondônia

Palavras-chave:

Prática social; Ensino de geografia; Educação

Key-Words:

Geography; Exploration; Creativity; Training;

Practice Teaching. 


\title{
Introdução
}

A Lei 9.394/96, de Diretrizes e Bases da Educação LDB conceitua educação como todos os processos formativos que se desenvolvem na convivência humana e em diferentes instituições. O termo gerador na LDB é por excelência a "convivência humana" em todos os momentos seja na família, "no trabalho, nas instituições de ensino e pesquisa, nos movimentos sociais e organizações da sociedade civil e nas manifestações culturais," isto é, a educação se desenvolve num amplo processo, ininterrupto de aprendizagem. Carlos Rodrigues Brandão nos lembra que:

\begin{abstract}
Ninguém escapa da educação. Em casa, na rua, na igreja ou na escola, de um modo ou de muitos todos nós envolvemos pedaços de nossas vidas com ela: para aprender, para ensinar, para aprender e ensinar. Para saber, para fazer, para ser ou para conviver, todos os dias misturamos a vida com a educação. Com uma ou com várias: Educação? Educações. (BRANDÃO, 1989: 7)
\end{abstract}

Por outro lado (APLLE, 2007:94), nos ensina que "a educação é um lugar de conflito e de compromisso". Nessa perspectiva a educação escolar tem importantes contribuições na formação dos indivíduos, pois, sendo ela uma composição harmoniosa de objetivos educacionais, os embates que a permeiam serão também os responsáveis pela formação política dos educandos. O sentido de política aqui empregado se refere não a uma formação partidária, mas ao caráter político que cada componente em particular tem a oferecer. E nesse sentido, é necessária e urgente que professores de diferentes níveis de ensino possam iniciar uma conversa a respeito das contribuições que cada área tem a oferecer e em conjunto pensar uma resposta para o problema do isolamento didático entre as disciplinas escolares.

No ensino da geografia escolar muitos dos livros e textos, se propõem a demonstrar que a Geografia se inter relaciona com as áreas do conhecimento e que essa inter relação faz dela uma ciência interdisciplinar. Chama atenção o fato que tanto Geografia quanto as áreas que com ela se inter relacionam nem sempre coadunam na interdisciplinaridade, ficando apenas a tentativa de explicação.

Pensar a geografia escolar no contexto da educação significa buscar novas e velhas maneiras para ensinar e para aprender. Exige que o professor detenha um conhecimento mais amplo de sua e de outras áreas do conhecimento e, portanto, a capacidade para ir além do que já está posto. Encontrar não fórmulas prontas, mas metodologias capazes de possibilitar ao professor um aprendizado que eleve sua formação a um patamar de conhecimentos necessários que darão suporte ao processo de ensinar-aprender.

Não é objetivo deste trabalho, criar um conceito de Geografia, mas iniciar uma reflexão pensando na importância que o conhecimento geográfico representou para as populações primitivas, para o contexto histórico do processo de formação da ciência geográfica, situá-la como componente curricular obrigatório nas escolas brasileiras e, a partir desse enfoque tecer algumas considerações a respeito da prática social dos professores e, relacionar o ensino da geografia escolar à Pedagogia Histórico-Crítica como suporte metodológico capaz de fornecer importantes contribuições para o ensino e para a aprendizagem.

Geografia Ensino \& Pesquisa, v. 17, n.2 p. 117-128 maio./ago. 2013.

Prática social: uma estratégia para ensinar e aprender a geografia escolar

\section{O que é Geografia?}

Essa pergunta permeia quase todos os livros didáticos e é repetida anualmente pelos professores ou pelos alunos, na maioria das salas de aula do país. Responder a essa indagação significa enveredar por diversos caminhos, onde, por vezes eles se entrelaçam e por vezes, se separam. 
Ao tentar uma resposta que dê conta desse entrelaçamento, toma-se por base a afirmação de Humberto Maturana (2001:61), para quem "tudo o que se observa depende do observador," o que, de certa forma, pressupõe pensar a Geografia pela via do senso comum. Não, a geografia não está sendo reduzida a essa categoria. Esta é apenas uma maneira de dizer que a ciência geográfica não se enquadra na categoria da simples observação. Entretanto, se pensada para uma situação de entendimento pode-se apelar para o que se entende por ou, para o que é visível por todos, ou ainda, para indicar questões ou temáticas por ela trabalhadas.

Dessa forma e sabendo-se que os conhecimentos adquiridos pelo senso comum são tratados como representação e que toda representação social remete ao reconhecimento de que nela se apresenta indistintamente o comum e o científico, solicita-se permissão do leitor para apresentar um poema geográfico intitulado "Geografia Indígena”, composto em 1992, por professores indígenas do Acre e sudeste do Amazonas, que, por sua vez responde parte da indagação inicial.

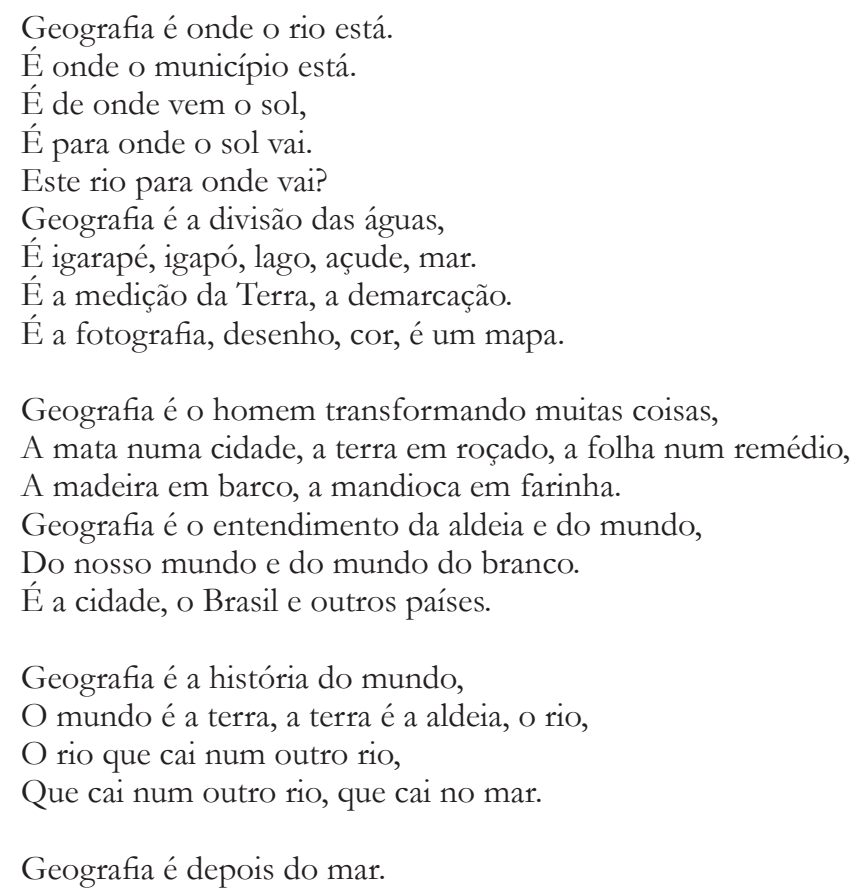

$\mathrm{Na}$ segunda situação, "quando por vezes se separam" pensa-se a Geografia como ciência, fundamentada em pressupostos teóricos e metodológicos.

Por um lado responder a pergunta "o que é Geografia" parece, a princípio, ser essa uma pergunta de fácil resposta. Por outro lado, tal facilidade se desfaz a medida que se investigam os fundamentos teóricos e metodológicos que lhes confere a categoria de ciência. Portanto, responder a essa pergunta não parece tão simples assim, pois a Geografia é uma ciência e toda ciência tem sempre um conjunto conceitual que no mínimo dificulta uma resposta certeira.

O que está muito ausente nas salas de aulas não é a tentativa de dar uma resposta concreta ao conceito de Geografia. Está sim, ausente dos livros didáticos e do discurso do professor dessa disciplina o questionamento central que permite entender seu verdadeiro sentido. Trata-se então de perguntar também "para quem serve e de quem a Geografia está a serviço."

Talvez perguntar "para quem serve e de quem a Geografia está a serviço," incomode muito mais. Nesse sentido Moreira (1988) afirma que

Geografia Ensino \& Pesquisa, v. 17, n.2 p. 117-128 maio./ago. 2013. 
se-á, no plano da política internacional, como intensa luta entre as potências imperialistas pela divisão dos continentes em "zonas de influência." (MOREIRA,1988:7).

Moreira se refere à Conferência Internacional de Geografia, realizada em Bruxelas no ano de 1876, sob a presidência do rei Leopoldo II, como reveladora do papel político e ideológico da Geografia naquele momento.

A Conferência de Bruxelas revelará o papel que sempre estivera reservado à Geografia e suas instituições, e as razões por que se tornara um saber de grande prestígio junto aos governos. Por isso não deixará de ser outro o desdobramento da reunião das sociedades geográficas: a criação da Associação Internacional Africana (AIA), e que (...) com o concurso das sociedades geográficas empreender-se-á o avanço imperialista sobre a África, Ásia e Oceania, bem como a América Latina, esta já submetida à dominação colonial desde o século XVI. (MOREIRA, 1988:8).

Outra tentativa de resposta "para quem serve e de quem a Geografia está a serviço" é fornecida pelo geógrafo francês Yves Lacoste, que em 1970, escreve a obra - "Geografia: isso serve antes para fazer a guerra." Nela, Lacoste denuncia a existência de uma Geografia dualista: a Geografia do Estado e a geografia dos professores, indicando dessa forma, para quem serve e de quem a Geografia está a serviço. A percepção de uma Geografia dualista responde outra questão. A geografia dos professores, ligada a tendência tradicional, nunca esteve a serviço da formação social dos educandos.

\section{A evolução do pensamento geográfico}

O conhecimento geográfico para os povos primitivos não representava mais que um ponto conhecido, um local de caça, local de existência de água, uma caverna; um caminho, de deslocamento das pessoas, das manadas, uma trilha conhecida para onde iam e vinham nossos ancestrais. Representava, entretanto o conhecimento de diferentes lugares. Tal conhecimento era vital para a sobrevivência daqueles povos. Posteriormente ao conhecimento geográfico acrescenta-se: uma ilha, um porto, uma cidade, um continente, um país, um lugar.

A percepção evolutiva desse conhecimento como Geografia surge entre os povos na antiguidade oriental, entre eles os gregos e os romanos.

Durante a Idade Média as grandes viagens terrestres e ultramarinas garantiram a descoberta e a anexação de novas terras, proporcionando o conseqüente aumento dos territórios e das riquezas nas metrópoles. O processo de anexação de novos territórios resultou na produção de novos conhecimentos e saberes, como por exemplo, novas formas de organização e reorganização do espaço, o que de fato possibilitou a apreensão e a construção de um novo conhecimento do mundo a partir da criação ou da recriação dos espaços. A expansão do capitalismo, entretanto, foi o grande viés para a propulsão do conhecimento geográfico.

Se por um lado os povos primitivos foram os responsáveis pelas primeiras impressões

Geografia Ensino \& Pesquisa, v. 17, n. 2 p. 117-128 maio./ago. 2013.

Prática social: uma estratégia para ensinar e aprender a geografia escolar humanas na natureza de que se têm notícias, fazendo do território conhecido sua área de sobrevivência o que mais tarde viria a ser contado como evidências geográficas, por outro, seus precussores, sistematizadores do conhecimento acumulado e os fundadores da ciência geográfica moderna, que por meio de suas reflexões foram os responsáveis pela elevação da geografia ao status de ciência, não se pode esquecer os críticos modernos e pós- modernos que sempre a alerta, indicam os pontos obscuros e que merecem ser clarificados no interior dessa ciência.

A inserção da ciência geográfica no plano acadêmico é recente e, é sob os auspícios ideológicos da intervenção imperialista do capital que a Geografia se transforma em disciplina 
acadêmica, estando a formação dos primeiros geógrafos sob a responsabilidade de não geógrafos. É também sob a égide imperialista e com objetivos laureados pela ideologia do capital que a Geografia se transforma em disciplina escolar. Seu papel na escola deve inicialmente servir prioritariamente para a difusão da ideologia do nacionalismo patriótico, pelo viés da formação de cidadãos.

Nas últimas décadas do século XX, a ciência geográfica passa por muitas transformações, principalmente a partir da chamada Geografia Nova, quando se produzem alterações significativas nessa ciência. A proposta de uma Geografia Crítica, iniciada com obra Geografia: isso serve antes para fazer a guerra, de Yves Lacoste (1970), denunciando a existência de uma geografia dual conhecida como: a geografia do estado e a geografia dos professores o que permitiu a anexação de críticas, não somente ao sistema educativo, mas, principalmente no ensino da geografia escolar. Na década de 1970, no Brasil, Milton Santos, lança a obra Por uma Geografia Nova (1978), cujos desdobramentos permitiram um novo direcionamento acadêmico, seja na formação do geógrafo seja na formação do licenciado. Inegável, a contribuição dessa corrente para o movimento de renovação pelo qual passou a Ciência Geográfica, que hodiernamente permite olhá-la de um ponto de vista mais amplo, incluindo nela, às relações sociais. Para Moreira, citado por Cavalcante (1998, p. 21), Lacoste teve o papel de dar impulso inicial às reflexões para a renovação da Geografia no Brasil. Nesse mesmo sentido Cavalcante, (1998) considera que

\begin{abstract}
o movimento do ensino de geografia, dentro do movimento mais amplo de renovação, teve, pois, como interlocutoras as "geografias" vigentes no momento, ou seja, a Geografia Tradicional e a Geografia Quantitativa. Fazendo a crítica destas correntes da Geografia e de suas implicações no ensino surgiram propostas de incorporar as reflexões da concepção dialética no ensino, o que possibilitou a emergência da chamada Geografia Crítica (1998, p. 19 e 20).
\end{abstract}

Mesmo com todo o conhecimento geográfico produzido na academia no período, poucas foram as mudanças introduzidas na geografia escolar, continuando nas salas de aulas o mesmo modelo tradicional de ensino.

A ausência da Geografia Crítica na escola merece algumas considerações. Por um lado, as discussões acadêmicas sobre a produção do conhecimento pouco chega até as escolas, pois existe ainda um hiato entre a fonte produtora e a fonte consumidora do conhecimento. Isso está explícito pelas formas como um e outro acontecem. No caso da corrente crítica da geografia que se forja na academia nos anos de 1960/70 encontra a resistência da própria escola que ainda desconhece outros caminhos para ensinar. Por outro lado, a adoção de nova forma de ensinar exige o conhecimento de uma pedagogia que sustente a produção do conhecimento em área específica e, a academia não percebeu a importância da relação educação geográfica e ensino, cujas bases se forjam na ciência geográfica e nas ciências da educação.

Nesse sentido, no seio do movimento mais amplo de renovação da educação mundial, a tendência progressista, de base marxista, reúne diferentes propostas pedagógicas críticas, que segundo (LUCKESI, 1994:64) tem se manifestado em três tendências: a "libertadora, mais conhecida como de Paulo Freire, a libertária, que reúne os defensores da autogestão pedagógica e a crítico-social dos conteúdos."

No interior da corrente progressista "crítico-social dos conteúdos", se delineia também na década de 1970, a Pedagogia Histórico-Crítica cujos objetivos se propõe a sustentar o ensino, a pesquisa e a extensão no campo da educação.

Retomando a questão do ensino da Geografia no seio do movimento de crise da Geografia Tradicional e o conseqüente movimento de transição para a Geografia Crítica, é possível perceber que o distanciamento entre a tendência crítica da Geografia e as tendências

Geografia Ensino \& Pesquisa, v. 17, n.2 p. 117-128 maio./ago. 2013.

Botelho, J. M. L

ISSN 2236-4994 
pedagógicas, também críticas, dificultou o ingresso da Geografia crítica em sala de aula. O fosso entre as áreas produtoras do conhecimento, na própria academia, recai sempre na formação docente, responsável por fazer ou não a ligação entre a academia e a escola.

\section{Situando a Geografia no ensino oficial brasileiro}

A partir do ingresso da Geografia como disciplina escolar obrigatória no Brasil, em 1837, no Colégio Pedro II, na cidade do Rio de Janeiro, três importantes momentos em sua trajetória merecem destaque: a elevação da Geografia ao status de disciplina universitária, sua obrigatoriedade no ensino primário e secundário a partir da reforma Capanema e o movimento de renovação na década de 1970/80.

O primeiro se refere ao momento em que a Geografia alcançou o status de disciplina universitária, com implantação de cursos superiores de Geografia ocorrida a partir de 1930, nas cidades do Rio de Janeiro, Porto Alegre, Recife e Salvador, com destaque para a criação da Faculdade de Filosofia, Ciências e Letras da Universidade de São Paulo. O segundo momento se dá pela sua implantação como disciplina do currículo oficial no ensino primário e secundário do País a partir da promulgação da Lei Orgânica do Ensino Primário, mais como Reforma Capanema em 1946, pelo Decreto-lei 8.529, de 02 de janeiro de 1946, posteriormente assegurada nas sucessivas reformas educacionais gerais. Um terceiro momento se refere ao movimento de renovação da ciência geográfica, notadamente pela proposta crítica da geografia.

Com a implantação da Lei 4.024/61, de Diretrizes e Bases da Educação Nacional LDBEN o ensino de geografia tornou-se obrigatório em todos os currículos das escolas brasileiras. Na vigência da Lei 5.692/71, conhecida como a reforma da reforma da educação, o ensino de Geografia escolar perde seu status de disciplina, sendo substituída pela recém criada disciplina de Estudos Sociais.

Com a reforma educacional empreendida pela Lei 9.394/96, de Diretrizes e Bases da Educação a Geografia retorna como disciplina obrigatória em todos os níveis e modalidades da Educação Básica. A referida lei também assegura no artigo 2. ${ }^{\circ}$, inciso III, o "pluralismo de idéias e de concepções pedagógicas" em todos os níveis de ensino. Nesse sentido o pluralismo de concepções pedagógicas legalmente proposto se apresenta como nova possibilidade de novas práticas de ensino da geografia escolar.

\section{Prática social: algumas conceituações e entendimentos}

Geografia Ensino \& Pesquisa, v. 17, n.2 p. 117-128 maio./ago. 2013.

Prática social: uma estratégia para ensinar e aprender a geografia escolar prática social considerada na perspectiva do pensamento dialético é muito mais ampla do que a prática social de um conteúdo específico, pois refere-se a uma totalidade que abarca o modo como os homens se organizam para produzir suas vidas expresso nas instituições sociais do trabalho, da família, da escola, da igreja, dos sindicatos dos meios de comunicação social, dos partidos políticos, etc. (GASPARIM, 2003:21) 
De acordo com a citação distinguem-se dois entendimentos na pratica social: primeiro toma o conteúdo de ensino escolar e a partir dele propõe o desenvolvimento de uma prática; o segundo se refere a um sentido mais amplo conduzido como um processo de totalidade, isto é, como um processo de formação integral do indivíduo. Em ambos os momentos, seja a prática social proposta inicialmente pensada a partir do conteúdo de ensino, seja a prática social como processo que se desenvolve em todos os momentos da vida escolar ou não, vislumbra-se a dialética como inter locutora.

Por sua vez (KIMURA, 2008:120), afirma que "as práticas sociais se referem às atividades que cada um realiza na sociedade na qual vivemos, o que significa tratar-se de uma ampla rede de interações de que participamos." Partindo da indicação de que a educação se desenvolver na e para a sociedade pode-se concluir que toda prática educativa é uma prática social. Nessa direção, é preciso pensar nas práticas educativas como sendo práticas sociais educativas e ao mesmo tempo educadoras. Pode-se arrolar nesse conjunto aquelas "práticas" que se desenvolvem por todo o ano letivo, por todo o curso, etc... sem que nela se verifique a consecução de objetivos. $\mathrm{Na}$ análise das práticas sociais no campo da educação é preciso ser mais cauteloso.

Considera-se neste trabalho a prática social como toda ação pedagógica capaz de proporcionar aos professores e aos alunos, ferramentas teóricas e metodológicas que lhes permitam a construção de seus próprios conhecimentos, de modo que possam atuar em todos os momentos de suas vidas como cidadãos autônomos, críticos e participativos. Em outras palavras, a prática social pode ser entendida como uma possibilidade metodológica de que o professor dispõe para atuar juntamente com seus alunos no conhecimento da realidade na qual estão inseridos: professor, alunos, escola e comunidade.

\section{A pedagogia histórico-crítica: prática social como caminho metodológico}

A Pedagogia Histórico-Crítica, segundo Saviani (1993), adota o paradigma metodológico da concepção dialética e tem por objetivo principal a re-significação dos conteúdos escolares por meio da prática social. A base marxista da produção do saber é a construção de conhecimentos a partir da transformação da sociedade, onde a historicidade sempre presente constitui o marco inicial. Nesse sentido e conforme Corazza (1991) citado por Gasparim (2003),

o conhecimento se origina na prática social dos homens e nos processos de transformação da natureza por eles forjados e agindo sobre a realidade os homens a modificam, mas numa relação dialética, esta prática produz efeitos sobre os homens, mudando tanto o seu pensamento, como sua prática. (p. 84).

Para Saviani (1993), no processo de desenvolvimento da prática social se distinguem dois momentos importantes: o da prática social inicial e o da prática social final. A prática social inicial é o momento em que professor e aluno estudam, planejam e tomam decisão sobre quais procedimentos adotar em relação ao estudo e a aplicabilidade do conteúdo frente aos problemas que se apresentam na realidade. A prática social final é o momento em que professor e aluno já detêm diferenciados níveis de conhecimentos sobre o conteúdo e sobre sua aplicação prática, novamente estudam e planejam as práticas sociais interventoras da realidade estudada.

Nesse sentido, a produção do conhecimento se dá num processo dinâmico que envolve o conteúdo, objeto de estudo; instrumentos materiais e não materiais, técnicas metodológicas, competências e habilidades técnicas do professor. Observa-se, pois o desenvolvimento de três fases de ensino e de aprendizagem que se envolvem e se interligam formando um todo: a fase sincrética, onde o conhecimento apresenta-se difuso; a fase da análise, quando são

Geografia Ensino \& Pesquisa, v. 17, n.2 p. 117-128 maio./ago. 2013. 
desmontadas e novamente reunidas todas as partes consideradas e, a fase da síntese quando o conhecimento já evoluiu permitindo as aproximações e distanciamentos entre a teoria e a prática. Corazza (1991) apud Gasparim (2003:5) observa que

O conhecimento como movimento parte da síncrese (sensorial concreto, o empírico, o concreto percebido), passando pela análise (abstração, separação dos elementos particulares de um todo, identificação dos elementos essenciais, das causas e contradições fundamentais) e chegando na síntese (o concreto pensado, um novo concreto mais elaborado, uma prática transformadora) (p.7).

\section{Repensando a prática social no ensino da Geografia}

A educação pensada a partir de seus objetivos gerais de ensino, pensa-se naqueles objetivos primordiais para todo o conjunto da educação, que envolvem a formação da identidade, a formação para a cidadania, o desenvolvimento da autonomia intelectual e a promoção de atitudes de respeito, entre outros, propostos para a formação integral do educando. A consecução desses objetivos depende do desenvolvimento de capacidades que permitam a cada aluno perceber a sociedade em que vive como construção humana e a si mesmo como sujeitos do processo.

O componente geografia escolar é por execlência chamada a contribuir na construção da identidade pessoal e social, na formação da cidadania e no desenvolvimento da autonomia intelecutal e ao mesmo tempo proporcionar atitudes de respeito e solidariedade do educando, compondo um cidadão crítico, criativo, cooperativo e sensivo aos problemas sociais que enfrenta na sociedade, devendo portanto, assumir maior compromisso.

Assim, a Geografia escolar assume especial atenção para o estudo da interação entre a sociedade e a natureza, não permitindo, pois, que se estabeleça a dissociação entre a teoria e a prática, de forma que a partir das aprendizagens teóricas, e vice versa, sejam encaminhados os trabalhos de campo, a pesquisa e a extensão, enquanto ferramentas metodológicas que proporcionam a solidez dos conhecimentos adquiridos pelo conjunto teoria e prática. Para Kaercher (1999, p. 171), o ensino da Geografia

não deve se restringir às aparências do visível. Devemos procurar as causas, as origens dos processos que formam os espaços como eles são. Devemos procurar as causas, as origens dos processos que formam os espaços como eles são. Para tal, devemos estar muito atentos à ação concreta dos homens, pois são eles os construtores do espaço geográfico.

Geografia Ensino \& Pesquisa, v. 17, n.2 p. 117-128 maio./ago. 2013.

Prática social: uma estratégia para ensinar e aprender a geografia escolar as condições de existência dos próprios alunos e seus familiares são um ponto de partida que pode garantir que a compreensão do espaço geográfico se faça dentro de um processo que vá do particular ao geral. (...) Enfim, propiciar aos alunos a vivência de um método de trabalho que possa ser usado em diferentes situações. 
A citação acima enfoca dois pontos básicos: o primeiro é a preocupação com a compreensão dos conceitos; o segundo com o método. A preocupação com o método permite pensar que existe a possibilidade de se iniciar um ensino partindo do particular, do espaço vivido, relacionando o ensino às temáticas emergentes, tais como: políticas e novas territorialidades, gênero e ensino de geografia, turismo e ensino de geografia, violência urbana, meio ambiente, educação ambiental, entre outras que se apresentam como perspectivas atuais desafidoras na busca de novos rumos e de novas metodologias de ensino e de aprendizagem.

Nesse sentido, o ensino da Geografia precisa ser redimensionado utilizando-se de metodologias teórico-práticas, aqui entendida como prática social, de modo a permitir maior compreensão e aprendizado pelos alunos e forjar uma nova identidade para a Geografia escolar.

A educação geográfica escolar é componente curricular capaz de proporcionar importantes contribuições aos alunos por meio da prestação de serviços à comunidade envolvente, cujos resultados lhes permitam construir uma identidade própria a partir do conhecimento da realidade e das possibilidades propositivas na resolução dos problemas sociais, educativos ambientais, entre outros, pertinentes à formação social.

As propostas educativas nacionais atuais apostam num ensino centrado na construção de competências e habilidades que permitam ao educando utilizá-las nos diversos momentos de suas vidas para a resolução de problemas que cotidianamente se apresentam. Não se trata aqui de transformar o ensino da Geografia num ensino puramente técnico. Entretanto, para a aprendizagem de competências e habilidades e seus conseqüentes usos é necessário ensiná-las. De acordo com Vessentini citado por Cavalcante (1998, p.22),

\begin{abstract}
um ensino crítico de geografia não consiste pura e simplesmente em reproduzir num outro nível o conteúdo acadêmico; pelo contrário, o conhecimento acadêmico (ou científico) deve ser reutilizado, reelaborado em função da realidade do aluno e do seu meio (...) não se trata nem de partir do nada e nem simplesmente aplicar no ensino o saber científico; deve haver uma relação dialética entre esse saber e a realidade do aluno - daí o professor não ser um mero reprodutor mas um criador.
\end{abstract}

Vessentini (oc.cit) demonstra grande preocupação com a Geografia apropriada para o século XXI, e acrescenta:

\footnotetext{
o ensino de geografia de geografia no século XXI, portanto, deve ensinar, ou melhor deixar o aluno descobrir - o mundo em que vivemos, com especial atenção para a globalização e as escalas local e nacional, deve enfocar criticamente a questão ambiental e as relações sociedade/natureza (...) deve realizar constantemente estudos do meio (...) e deve levar os educandos a interpretar textos, fotos, mapas, paisagens.
}

Tanto no Ensino Fundamental quanto no Ensino Médio, existem estreitas relações entre a educação geográfica à realização de práticas sociais. A descoberta desse viés metodológico pelos docentes parece ser uma necessidade urgente para envolver e transformar as ações de sentido puramente didáticas em sentido de ações de trabalho pedagógico, científico e social, no sentido dialético, de transformação social, como cita Marx em sua famosa terceira tese sobre Feuerbach apud (LOUREIRO, 2004, p.89),

a doutrina materialista de que os homens são produto das circunstâncias e da educação, que homens diferentes são, portanto, produto de outras circunstâncias e de uma educação diferente, esquece que as circunstâncias são modificadas pelos homens e que o próprio educador deve ser educado.

Aqui a categoria trabalho, pedagógico e científico tem caráter de formação social dos
Geografia Ensino \& Pesquisa, v. 17, n.2 p. 117-128 maio./ago. 2013. 
educandos. De outra forma, relaciona-se a essa formação à teoria dialética que concebe todo o processo de produção do conhecimento tendo como ponto de partida e como ponto de chegada a prática social. Segundo Corazza citado por Gasparim, (2003 p.6) a teoria dialética do conhecimento se desenvolve a partir de três fases:

$\left.1 .^{\circ}\right)$ o processo de conhecimento tem como ponto de partida a prática social; 2. ${ }^{\circ}$ a teoria está em função do conhecimento científico da prática social e serve como guia para ações transformadoras e $3 .^{\circ}$ ) a prática social é o critério de verdade e o fim último de todo o processo cognitivo, a concepção metodológica dialética adota o mesmo paradigma, qual seja $-1 .^{\circ}$ partir da prática; $2^{\circ}$ ) teorizar sobre ela e $3 .^{\circ}$ ) voltar à prática para transformá-la.

E nesse sentido, pensar a Geografia enquanto prática social significa pensar novas formas de atuação desta ciência no espaço social dos sujeitos numa perspectiva de que como em qualquer outro aprendizado, a teoria sem a prática não será capaz de dar conta da formação dos principais conceitos que a Geografia se propõe a trabalhar. De outra forma, a prática social vista como suporte metodológico que permita ao professor, desenvolver sua própria capacidade para dirigir conscientemente as novas situações aprendizagens que na atualidade se apresentam, perpassa pela capacidade de sua própria formação continuada.

No caso do Ensino Médio, etapa final da Educação Básica, os objetivos de ensino têm como base consolidar e aprofundar os conhecimentos adquiridos no Ensino Fundamental. Nessa etapa de suas vidas os estudantes apresentam maturidade de conhecimentos e responsabilidades em grau sufuciente para desempenhar funções de liderança, seja no processo de aprendizagem seja no em qualquer outra dimensão social. Ora, se forem estimulados e orientados nesse sentido e se forem adotadas metodologias de ensino e de avaliação que estimulem suas iniciativas provavelmente estarão realizando aprendizado "significativo."

Para que uma aprendizagem seja significativa os conceitos, as atitudes, os valores e as habilidades devem ser ensinados e aprendidos por meio do "o quê," "do como," "do com o quê" e "do para quê." Em outras palavras, a adoção da prática social de atividades também sociais como metodologia capaz de re-significar a validade dos diferentes conteúdos escolares para a aprendizagem no presente e proporcionar a utilização destas como ferramentas para aprendizagens futuras, deve ser incentivada.

\section{Para não concluir}

Nem todo conteúdo ensinado e aprendido na escola pode ser pensado e transformado em categoria técnica, pura e simplesmente mas todas as técnicas utilizáveis no ensino proporcionam competência técnica e todas podem ser aplicadas no ensino de geografia. É preciso que o educador perceba primeiro e faça o aluno perceber que no espaço geográfico no qual, ele, os educandos e a escola está inserido, existem necessidades reais esperando por trasformação e a escola, pode e precisa fazer algo. A Pedagogia Histórico-Crítica se apresenta como possibilidades didáticas de ensino e de aprendizagm e que, no ensino de

Geografia Ensino \& Pesquisa, v. 17, n.2 p. 117-128 maio./ago. 2013.

Prática social: uma estratégia para ensinar e aprender a geografia escolar geografia são grandes as possibilidades de aplicação dos conteúdos seja no contexto social ou no contexto físico do espaço geográfico.

Assim, a prática social inicial na educação, como em qualquer outra situação, deve partir do trabalho inicial do educador, ou seja, transformar os conteúdos, objeto de estudo em objeto de conhecimento pelo e para o aluno. Para que isso ocorra é preciso que o educador sensibilize o educando para perceber as relações que existem entre o conteúdo a ser estudado e as necessidades, os problemas e os interesses que fazem partes de sua vida cotidiana. 


\section{Referências bibliográficas}

ANDRADE, Manoel C. de. Geografia: Ciência da Sociedade. Uma introdução à análise do Pensamento Geográfico. 2a edição. São Paulo: Atlas. 1992. 143p.

APLLE, Michael. A educação e os novos blocos hegemômicos. In: RODRIGUES, Alberto Tosi: Sociologia da educação. 6. ed. Rio de Janeiro: Lamparina, 2007.

BOTELHO, José Maria Leite. Ensino de Geografia e Educação Ambiental. PRESENÇA N.0 19 e 20 mar./jun. 2.000 .

BRANDÃO, Carlos Rodrigues. O que e Educação. 23. ed. São Paulo: Brasiliense, 1989.

CAVALCANTE, Lana de Souza. Geografia, escola e construção do conhecimento. CampinasSP: Papirus, 1998.

CARLOS, Ana Fani; OLIVEIRA, Ariovaldo U. (org). Reformas mundo da educação: parâmetros curriculares e geografia. São Paulo: Contexto, 1999.

CARLOS, Ana Fani. Os caminhos da reflexão sobre a cidade e o urbano. São Paulo: Edusp, 1994.

CASTELLAR, Sônia (org.). Educação geográfica: teorias e práticas docentes. São Paulo: Contexto, 2005.

CASTROGIOVANNI, Antônio Carlos (org). Geografia em sala de aula: práticas e reflexões. Porto Alegre: AGB, 1998.

CORAZZA, S. M. "Manifesto por uma dia-lé-tica”. Contexto e Educação, Injuí, vol. 6, n. 22, pp. 83-99, abr.jun.

GASPARIN, João Luiz. Uma didática para a pedagogia histórico-crítica. 2. ed. Campinas - SP: Autores Associados, 2003.

KAERCHER, Nestor André. (orgs.). Geografia em sala de aula: prática e reflexões. 2. ed. Porto Alegre: UFRGS/AGB, 1999.

KIMURA, Shoko. Geografia no ensino básico: questões e propostas. São Paulo: Contexto, 2008.

LOUREIRO, Carlos Frederico B. Trajetória e Fundamentos da Educação Ambiental. São Paulo: Cortez, 2004.

LUCKESI, Cipriano Carlos. Filosofia da Educação. São Paulo: Cortez, 1994. (Coleção magistério de 2. ${ }^{\circ}$ Grau. Série formação do professor).

MATURANA, Humberto. O que se observa depende do observador. In: GAIA: Uma Teoria do Conhecimento. Org. William Irwin Thompson. 3. ed. São Paulo: Gaia, 2001

MOREIRA, Ruy. Para onde vai o pensamento geográfico: por uma epistemologia crítica. São Paulo: Contexto, 2006.

Geografia Ensino \& Pesquisa, v. 17, n. 2 p. 117-128 maio./ago. 2013.

MOREIRA, Ruy. O que é Geografia? São Paulo: Brasiliense, 1988. 
PONTUSCHKA, Nídia Nacib, OLIVEIRA, Ariovaldo Umbelino de. (orgs.). Geografia em Perspectiva. 3. ed. São Paulo: Contexto, 2006.

SAVIANI, Dermeval. Escola e Democracia. 32. ed. Campinas: Autores Associados, 1999.

\section{Correspondência:}

José Maria Leite Botelho - Av. Calama, 430. 76.801-188. Porto Velho - Rondônia - Brasil

E-mail: josemariabotelho@yahoo.com.br

Recebido em 12 de julho de 2012.

Aceito para publicação em 06 de março de 2013. 